\title{
E- and F-region coupling between an intense sporadic $E$ layer and a mesoscale traveling ionospheric disturbance
}

\author{
W. E. Swartz ${ }^{1}$, M. C. Kelley ${ }^{1}$, and N. Aponte ${ }^{2}$ \\ ${ }^{1}$ School of Electrical and Computer Engineering, Cornell University, Ithaca, New York, 14853, USA \\ ${ }^{2}$ Arecibo Observatory, Arecibo, 00612, Puerto Rico
}

Received: 14 October 2008 - Revised: 18 May 2009 - Accepted: 5 June 2009 - Published: 19 June 2009

\begin{abstract}
Considerable controversy exists concerning the relative roles of the $\mathrm{E}$ - and F-regions in controlling irregularity formation in the mid-latitude ionosphere, largely because electric fields due to a plasma instability in one region may map to the other if the perpendicular scales are sufficiently large. In this paper we look at a particularly fortuitous data set in which both E- and F-region observations were made using incoherent scatter radar, GPS, lidar, and coherent scatter radar. In this event, a dense, patchy sporadic E layer was detected that exhibited type I (two-stream) coherent echoes while, at the same time, the F-layer plasma was highly structured with plasma drifts of hundreds of $\mathrm{m} / \mathrm{s}$. We examine this event in the context of a mesoscale traveling ionospheric disturbance. The data presentation will be followed by comparison with current theories for coupling between these two regions.
\end{abstract}

Keywords. Ionosphere (Ionospheric irregularities; Midlatitude ionosphere)

\section{Introduction}

A discussion concerning the roles of the E- and the F-regions in forming irregularities in the mid-latitude ionosphere has been ongoing for over 50 years (Martyn, 1953). A major contribution was made by Farley $(1959,1960)$ when he described how electrostatic fields mapped from one region to the other. In brief, electric fields map along magnetic field lines for distances of the order of $\ell\left(\sigma_{0} / \sigma_{P}\right)^{1 / 2}$ where $\ell$ is their horizontal scale and the ratio is of the parallel conductivity to the cross field Pedersen conductivity. This relation operates in both directions in the sense that either region may map to the other. This in turn means that the electric fields

Correspondence to: W. E. Swartz (wes@ece.cornell.edu) due to a plasma instability in one region may map to the other if the perpendicular scales are sufficiently large.

As a rule of thumb, structures tend to be larger the higher up in the ionosphere they form. In the vertical the F-region scale size is a few times the neutral scale height, which is $50 \mathrm{~km}$ or so. Horizontal scales in the F region tend to be in the range of hundreds of $\mathrm{km}$. In the $\mathrm{E}$ region the scale height is much smaller and, in addition, the existence of metallic ions leads to vertical plasma scale sizes as small as $1 \mathrm{~km}$. Of course, instabilities tend to create situations where nonlinear mixing locally creates smaller scales, often into the meter scale.

Due to the high conductivity along the magnetic field, $\mathbf{B}$, we usually discuss irregularity scale sizes in the plane perpendicular to B. Our goal here is not to discuss the large scale traveling ionospheric disturbances (LSTIDs), which roll from the auroral zone carried by wave-induced neutral perturbations, but rather, to discuss processes that are fundamentally mid-latitude in origin. These are called medium or mesoscale traveling ionospheric disturbances (MSTIDs). Airglow observations indicate an outer scale of $600 \mathrm{~km}$ and a range of primary scales of 100-600 km (Mendillo et al., 1997; Garcia et al., 2000a, b), which travel characteristically from northeast to southwest at speeds the order of $100 \mathrm{~m} / \mathrm{s}$ (Garcia et al., 2000a) in the Northern Hemisphere. The structures are electrified (Behnke, 1979; Saito et al., 1995; Kelley et al., 2000b; Otsuka et al., 2004) and map from hemisphere to hemisphere. These results confirm many conclusions based on ionosonde observations of corrugations on the bottomside of the F layer (Bowman, 1981). MSTIIDs sometimes steepen on one edge and become structured on the other due to secondary instabilities (Kelley et al., 2002). The latter processes are thought to be due to secondary wind or electric field-driven $\boldsymbol{E} \times \boldsymbol{B}$ instabilities. The result is a power law irregularity form that has the form $k^{-3.5}$ (Saito et al., 1995), which is steeper than that found in equatorial instabilities and that found for density profiles of this day at

Published by Copernicus Publications on behalf of the European Geosciences Union. 


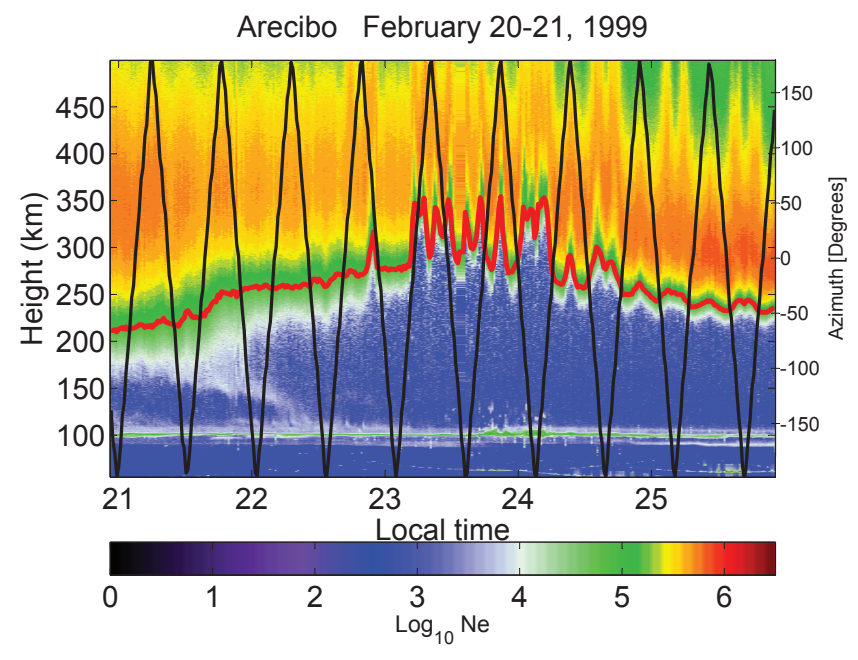

Fig. 1. Electron density through the disturbed night of 20-21 February 1999 with the azimuth position shown by the black triangular line. (Adapted from Fig. 7 of Swartz et al. (2002).)

Arecibo (Kelley et al., 2004). Horizontal structure in the E region is less well understood since airglow is not useful for plasma observations at E-region heights. However, neutral gas emissions do indicate horizontal scales of $10 \mathrm{~km}$ or so and, as we see in the next section, evidence points to similar scales in the plasma.

After discussing horizontal scales in the E region, we look at a particularly fortuitous set of observations in which both E- and F-region observations were made using incoherent scatter radar (ISR), GPS, lidar, and coherent scatter radar (CSR). This is followed by comparison with current theories for the coupling between these two regions.

\section{E-region horizontal structure}

A classic study by Miller and Smith (1978) used the Arecibo ISR in a scan mode to measure the plasma density as a function of altitude and horizontal scale. The usual sporadic E layers were found to be structured horizontally at scales of $3-10 \mathrm{~km}$ and to sometimes have structures reminiscent of those found in neutral gases subject to the Kelvin-Helmholtz Instability. A more recent example, and one that we concentrate on here, is presented in Fig. 1. Here a color scale shows the plasma density as a function of height (corrected from range at a zenith angle of $15^{\circ}$ ) and time/horizontal distance as the radar scans across the region for a five hour period (21:00 LT-01:00 LT). The triangular line shows the azimuth position. The azimuth was swung from $+180^{\circ}$ (south) through $+90^{\circ}$ (east) and on through $0^{\circ}$ (north), $-90^{\circ}$ (west), and to $-180^{\circ}$ (south). It then reversed as it swung back around to $+180^{\circ}$ (south) again as indicated by the triangular waveform. Early in the evening the bottomside of the F region exhibited small height variations as the azimuth ro-

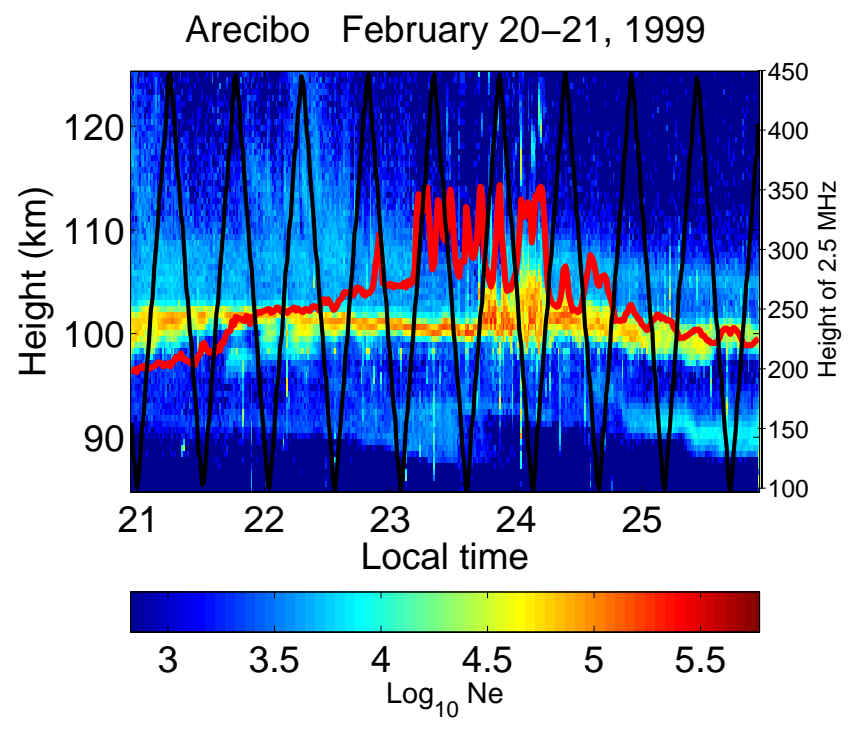

Fig. 2. Expansion of E-region electron densities with the azimuth position shown as in the previous figure. The right-hand axis refers to the heavy red line showing the height of the $2.5 \mathrm{MHz}$ contour following the bottomside of the $\mathrm{F}$ region. This $2.5 \mathrm{MHz}$ contour is also highlighted in Fig. 1. (Adapted from Fig. 12 of Swartz et al. (2002)).

tated and then after 23:00 LT extreme structuring suddenly commenced.

The lower altitude data is expanded in Fig. 2 also with the triangular curve showing the angular azimuthal location of the radar pointing direction used for the measurements. In this five hour period there were 19 passes around the azimuth (9+ each way) but about 20 maxima and minima in the plasma density. The plot also shows, with a different scale, the height variations of a particular plasma frequency contour $(2.5 \mathrm{MHz})$ on the bottomside of the F layer. The peakto-peak height variations in this contour were about $10 \mathrm{~km}$ early in the night but developed much larger excursions of $100 \mathrm{~km}$ or so at a time of increased E-layer density and eventual structuring.

Figure 1 of Swartz et al. (2002) shows that the field of view of the Arecibo radar for the $\mathrm{E}$ region is much smaller than for the F region. Also note that the CUPRI CSR field of view is always to the northwest and the Illinois CSR to the northeast of the ISR field of view in the E region. This makes exact correlations tricky in that the ISR radar never interrogates $\mathrm{E}$ and $\mathrm{F}$ regions on the same field line, let alone the volumes probed by the CSRs. The relationships between the regions probed by the ISR and the CSRs are illustrated in Fig. 3. The colored cones show the electron densities as a function of latitude, longitude, and altitude for sequential azimuth scans. The direction of each azimuth scan can be deduced from the times in decimal hours given at the ends of each scan. The hypotenuses of the red triangles with one side at ground level map the CSR beams going from the ground to 

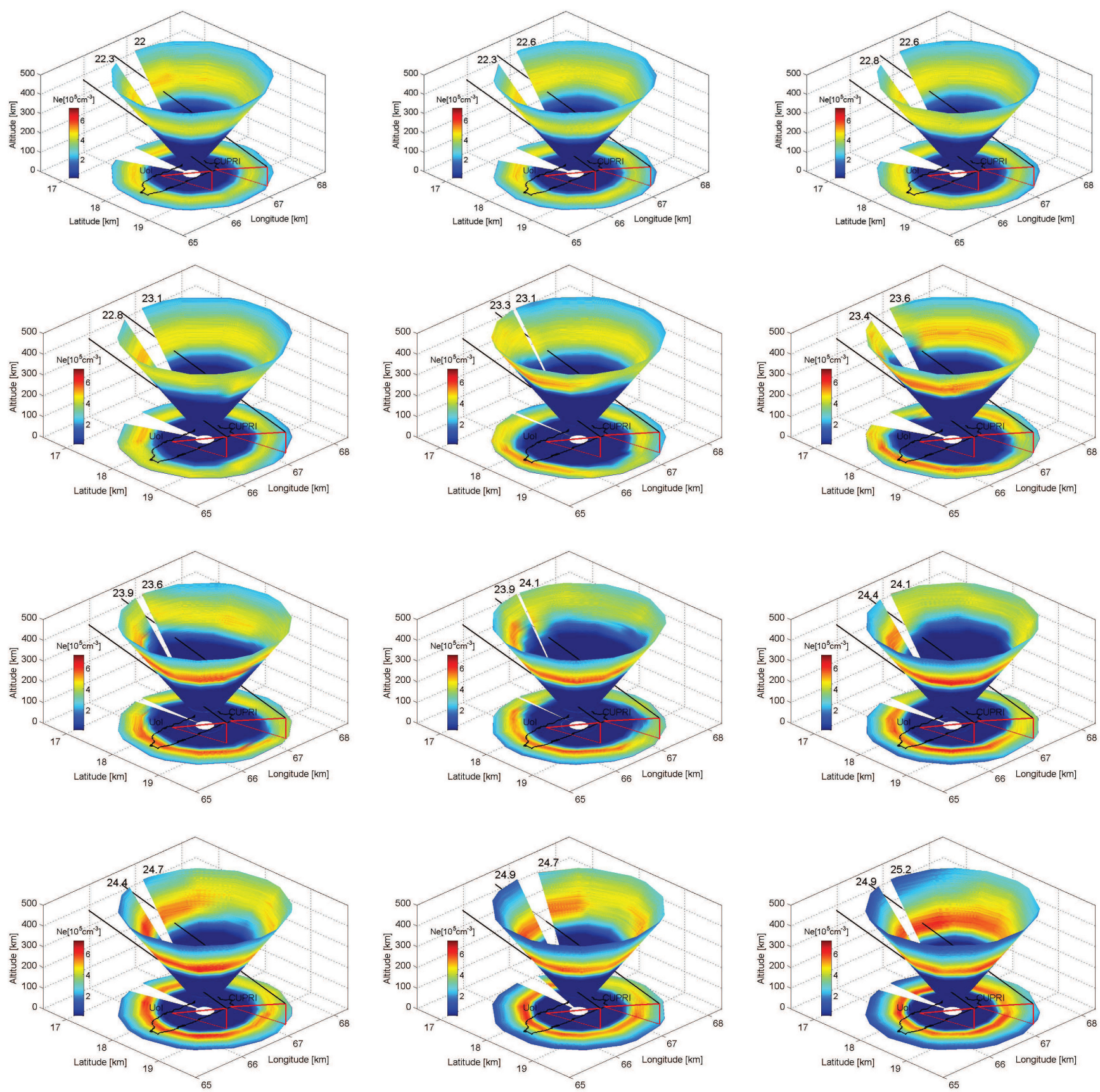

Fig. 3. Shown is a time sequence of sequential back-and-forth azimuth scan cones of the Arecibo electron density measurements from $55 \mathrm{~km}$ to $500 \mathrm{~km}$ together with the beams of the CUPRI and Illinois radars to $100 \mathrm{~km}$ altitude and the intersecting magnetic field lines. Time progresses from left-to-right and from top-to-bottom with beginning and ending times in decimal hours. Projections of the density cones are shown on the ground along with the outline of the island of Puerto Rico.

their respective $100 \mathrm{~km}$ altitude intersects. The heavy black lines from these intersect points show the magnetic field lines connecting the CSR volumes with the cones of ISR data. The ISR data are also projected onto the ground to better show the northern and southeastern regions that are masked by the 3-D cones.
A number of features are worth noting before examining details of the data shown in this format. The field line connected to the region probed by the Illinois radar penetrates the ISR cones above the E layer and exits the cones to the south through the bottom side of the F region. The corresponding CUPRI field line penetrates the cones at the bottom 


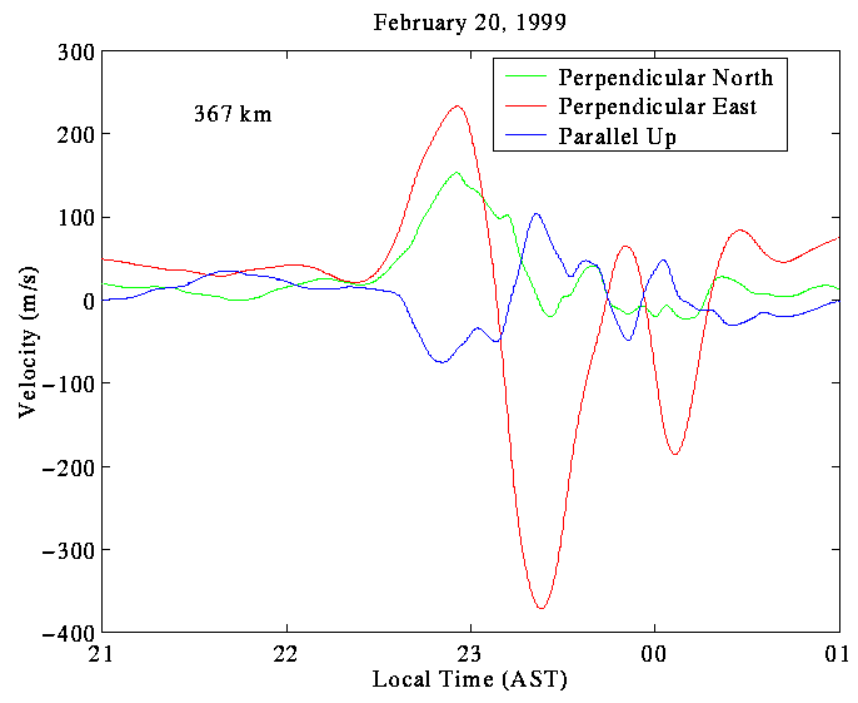

Fig. 4. Velocity components using the Sulzer et al. (2005). regularization at a height of $367 \mathrm{~km}$.

side of the F layer, and exits the cones near the peak of the normal $\mathrm{F}$ layer. When the layer is raised by the disturbance, the peak of the F layer moves above the south exit points, as shown especially in the 6th through the 9th cones where the yellow areas in the south-southwest sectors have risen to higher altitudes.

Now let us examine how the extreme disturbances shown in Fig. 1 unfold in the 3-dimensional presentations of Fig. 3. The first two cones are fairly symmetric in azimuth as confirmed by the cone projections onto the ground, but with somewhat denser ionization in the south. The second cone shows a very weak enhancement looking to the southeast. The 3rd cone shows an enhancement as yellow fills in to the upper rim of the east-northeast portion of the cone. It seems likely that this results from the north-east drift that existed from 22:30 to 23:00 (see Fig. 4). It is during the time of the 2nd and 3rd azimuth swings of Fig. 3 that strong coherent echoes were detected by the Illinois radar (see Fig. 6 of Swartz et al., 2002). Subsequently a strong drift component to the west develops and one can see a pink area of enhancement in the southeast of the 4th azimuth swing (see the ground projection), and enhanced yellow to the north. We suspect these two areas are connected by an elongated ridge of ionization aligned from the southeast to the northnortheast. By the 5th azimuth rotation, this ridge has moved to the southeast leaving a distinct valley in the north section of both the cone and its projection on the ground. The 5th cone also shows a new ridge (in pink) moving in from the east-northeast. (The beginning of this new enhancement was just beginning to show in the northeast of the 4 th cone.) By the time the azimuth swings back around from the east and northwest again, the new enhancement has intensified and moved west. Also the depleted region mentioned above has moved west and south. By the time of the 7th cone only a little of the original enhancement remains as indicated by the brighter yellow to the west and its connecting spot to the south. Major CUPRI echoes shown just prior to midnight in Fig. 1 of Swartz et al. (2002) occurred during the time of the 6th through the 8th azimuth swings. The 8th through the 12 th rotations show two more disturbances moving through the field of view. The eastern sides of the last four cones show a return to a fairly normal $\mathrm{F}$ layer while some residuals of the disturbance remain on the western side of even the last cone. Hence we see that the "extreme" variations shown in Fig. 1 are essentially due to the azimuth moving back-andforth through disturbances moving southwest at between 70 and $110 \mathrm{~m} / \mathrm{s}$ near the middle of the time sequence.

Another way to study horizontal structure is with low apogee rockets, which traverse the $\mathrm{E}$ layer at large angles to the vertical. In two such cases (Kelley et al., 1995; Pfaff et al., 2005), organization of the sporadic E plasma layer was found to be horizontally structured at scales of the order of $10 \mathrm{~km}$. These two flights were made during conditions now called quasi-periodic (Q-P) CSR echoes, in which the echoing regions are organized in regular bands (Yamamoto et al., 1992). In the Northern Hemisphere these bands are organized from northwest to southeast (Hysell et al., 2002, 2004) and travel to the southwest, much like F-region mesoscale TIDs, and just like what we have described here. The significance of this fact is explained later.

\section{E- and F-layer coupling in the 20/21 February 1999 event}

Next we summarize several additional aspects of the observations reported by Swartz et al. (2002):

1. The sporadic E layer shown in Figs. 1-3 there and Figs. 1 and 2 here was accompanied by Q-P CSR echoes with a time scale of $7-10 \mathrm{~min}$.

2. CSR E-region Doppler shifts as high as $355 \mathrm{~m} / \mathrm{s}$ were detected with several examples characteristic of (narrow) Type I echoes.

3. The F-region plasma density was also highly structured with height changes of up to $100 \mathrm{~km}$ during azimuth scans and TEC variations of 10 TEC units.

4. Spatially located line-of-sight velocities as high as $180 \mathrm{~m} / \mathrm{s}$ were detected in the $\mathrm{F}$ region which, when projected perpendicular to $\mathbf{B}$, yields westward velocities well over $300 \mathrm{~m} / \mathrm{s}$.

5. Both GPS and scanning radar observations indicate that two uplifted F-region structures separated by about $200 \mathrm{~km}$ passed over the region.

A technique has been developed at Arecibo to optimize the estimate of the vector ion drift when there is variability in 
time. The results of this regularization method (Sulzer et al., 2005) are shown in Fig. 4. Here we find a zonal drift perpendicular to the magnetic field oscillating in sign with a maximum close to $400 \mathrm{~m} / \mathrm{s}$. The perpendicular north and parallel up drifts display the usual anti-correlation (Kelley, 1989) with a net vertical upward velocity maximum at 23:00 LT of $75 \mathrm{~m} / \mathrm{s}$. When both component signs reversed, the flow remained upward with about the same value at 23:20 LT. This general trend of vertically upward net plasma flow is in agreement with the average uplift of the ionosphere of about $40 \mathrm{~km}$ during the interval 22:50 to 23:40 LT.

Every theory involving coupling between the $\mathrm{E}$ and $\mathrm{F}$ regions involves the conductivity in the two regions. In Fig. 5 we plot three field line-integrated Pedersen conductivities for the $\mathrm{E}, \mathrm{F}$ and E-region valley regions for $7 \mathrm{~h}$ just after sunset the F-layer conductivity was almost two orders of magnitude higher than the other two conductivities. After 20:00 LT the ratio began to decrease as the $\mathrm{F}$ layer rose in height and decreased in total content. By 23:00 LT, the F-region conductivity was only a factor of five higher. During this period there was no indication that either the $\mathrm{E}$ or $\mathrm{F}$ region had significant mesoscale structuring, although at smaller scales there does seem to be some structuring. Concerning the period near midnight when the E-region plasma density is highest and the large variations in the plasma and neutral parameters were observed, we notice that the F-layer and E-layer Pedersen conductivities begin to approach each other and, at 24:00 LT and for a short time thereafter, they are comparable. At the equator the layered vertical Hall conductivity, in the presence of a zonal electric field, causes a vertical polarization electric field that is an order of magnitude higher than the zonal field and which leads to the strong equatorial electrojet and to Type I radar echoes. We use this same effect below to investigate generation of high polarization electric fields and their role in generating high CSR Doppler shifts and Type I echoes.

\section{Discussion}

We ask first, with comparable E- and F-region Pedersen conductivities is it reasonable that the mesoscale electric fields could be generated in the $\mathrm{F}$ region which are large enough to create the fields responsible for the drifts shown around midnight in Fig. 4? The variations in the local F-region conductivity shown in Fig. 5 are about a factor of two, which has been observed before (Kelley et al., 2002). What sort of electric fields can be generated by the divergence of current due to these variations? Since $U>E / B \approx 150 \mathrm{~m} / \mathrm{s}$ for midlatitudes, $\boldsymbol{E} \times \boldsymbol{B}$ drifts as high a $300 \mathrm{~m} / \mathrm{s}$ are possible which is comparable to what is observed. However, with the local and conjugate contributions to the load, this estimate is probably high. In any case it is unlikely that direct drive of a two-stream instability by an F-region field is possible.

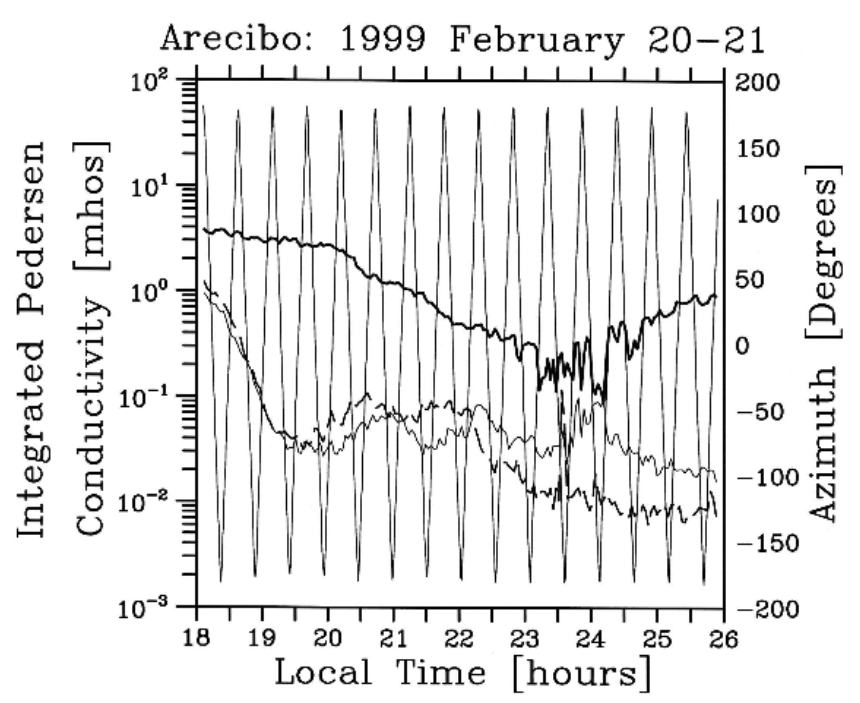

Fig. 5. E-region (light solid line), F-region (heavy solid line), and valley-region (dashed line) Pedersen conductivities.

Given the results of Hysell et al. (2004), we accept that Q-P E-region CSR echoing regions are organized in bands that are longer in their NW-SE direction than their direction perpendicular to that direction. It then follows from work by Shalimov et al. (1998), which in turn was inspired by the observations of Haldoupis and Schlegel (1996), that at least at times the midlatitude ionosphere behaved similarly to the equatorial ionosphere "on its side" (Haldoupis et al., 1997). Using this analogy, it is reasonable that polarizations of these elongated regions could lead to electric fields many times higher than those due to dynamo action or impressed from the $\mathrm{F}$ region as discussed above.

To explore this further consider an MSTID in the F-region oriented in the classic "Perkins" direction with a $\boldsymbol{k}$ vector $22.5^{\circ}$ south of due west. We associate this with the conditions for a neutral wind driven "instability" with a southward neutral wind $\left(U_{s}\right)$ equal to $50 \mathrm{~m} / \mathrm{s}$ and an eastward neutral wind $\left(U_{e}\right)$ of the same value. These are reasonable values for the mid-latitude pre-midnight period. MSTIDs exhibit height integrated F-region Pedersen conductivities, $\Sigma_{P}^{F}$, which are a factor of four or more higher in the high density, low altitude phase compared to the low density, high altitude phase (Makela and Kelley, 2003). For simplicity and clarity we take the high conductivity region to be uniform and the low conductivity region to be negligible. This is a square wave model for the MSTID. For the moment we take the E region to have a uniform conductivity.

In the high conductivity region, and including a polarization electric field $E_{P}$, it is straightforward but tedious to show that the component of the height integrated F-region Pedersen current parallel to the k-vector of the MSTID and due to the wind plus $E_{P}$ is,

$J_{k}=\Sigma_{P}^{F}\left[D-E_{P}\right]$ 


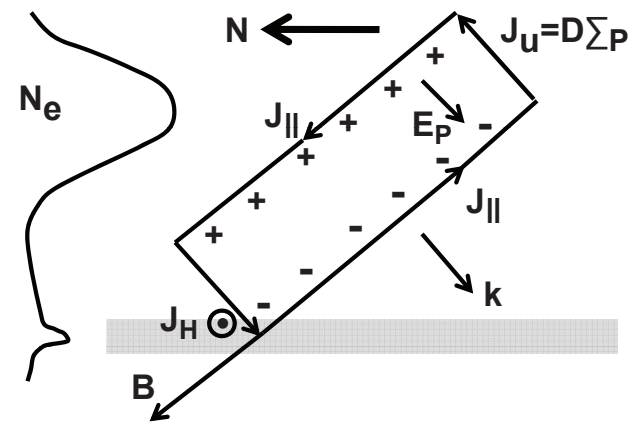

Fig. 6. Schematic showing the geometry of tilted ionization bands projected onto the magnetic meridian plane that can generate polarization electric fields large enough to drive two-stream instabilities when the integrated Hall conductivity exceeds the integrated Pedersen conductivity. Note that the vector $k$ is directed WSW and down.

where $D=-U_{s} B \cos (I) \cos \left(22.5^{\circ}\right)-U_{s} B \sin \left(22.5^{\circ}\right)$ is the driving equivalent electric field, $B$ is the total magnetic field $\left(4.2 \times 10^{-5} \mathrm{~T}\right)$ and $I$ is the dip angle (which we take to be $45^{\circ}$ ). Our model is illustrated in Fig. 6 where the elongated plasma bands of enhanced density at an angle west of geomagnetic north are projected onto the magnetic meridian. Note the wind driven current shown $\left(J_{u}=D \Sigma_{P}\right)$ does not include the portion driven by the polarization electric field. In this model the polarization field does not cancel the driving current due to the finite uniform E-region conductivity, $\Sigma_{P}^{E}$. In the square wave model the current sheet $J_{k}$ closes in the E region via connecting parallel currents and since our initial assumption is a uniform $\mathrm{E}$ region, we have

$\Sigma_{P}^{F}\left[D-E_{P}\right]=\Sigma_{P}^{E}\left[E_{P}\right]$

and

$E_{P}=\frac{\Sigma_{P}^{F} D}{\Sigma_{P}^{E}+\Sigma_{P}^{F}} \approx D$

since normally $\Sigma_{P}^{F} \gg \Sigma_{P}^{E}$. This result could have been anticipated but since the geometry is complicated, it is worth the effort to show some of the details.

Now the mapping of this electric field to the $\mathrm{E}$ region does not by itself make much of a difference for a uniform $E$ region since $E_{P}$ is not much larger than the normal dynamo electric field. But if we now posit that the $\mathrm{E}$ region is highly structured, as in fact is the case here and in other Arecibo observations (Miller and Smith, 1978), then the Hall current perpendicular to $E_{P}$ will not be divergence free and a secondary polarization electric field, $E_{p}^{\prime}$ will occur (Shalimov et al., 1998). Ignoring F-region shorting, we have

$E_{P}^{\prime}=\left(\frac{\Sigma_{H}^{E}}{\Sigma_{P}^{F}}\right) \frac{D \Sigma_{P}^{F}}{\Sigma_{P}^{E}+\Sigma_{P}^{F}}$

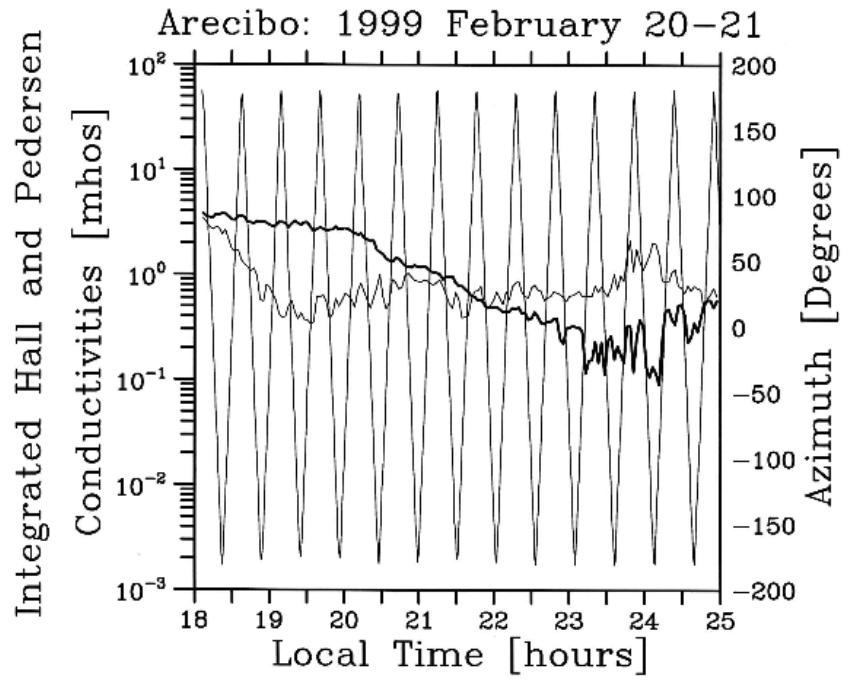

Fig. 7. Integrated Hall (light line) and Pederson (heavy line) conductivities.

If we allow some F-region shorting of this polarization electric field, we have, instead,

$E_{P}^{\prime}=\frac{D \Sigma_{H}^{E} \Sigma_{P}^{F}}{\left(\Sigma_{P}^{E}+\Sigma_{P}^{F}\right)^{2}}$

Now when $\Sigma_{P}^{F} \gg \Sigma_{P}^{E}$, either of these formulas yields

$E_{P}^{\prime} \approx \frac{\Sigma_{H}^{E}}{\Sigma_{P}^{F}} D$

For the parameters used above, $D=2.2 \mathrm{mV} / \mathrm{m}$.

Figure 7 shows the integrated Hall conductivity $\Sigma_{H}$ and the E-region Pedersen conductivity $\Sigma_{P}^{E}$. When things were most disturbed the Hall conductivity exceeds the Pedersen conductivity by about a factor of 10 . During the period 2341 to 2346 when strong type-I echoes were seen with CUPRI (Figs. 4 and 5 of Swartz et al., 2002), the westward perpendicular drift presented in Fig. 4 was waning from over $300 \mathrm{~m} / \mathrm{s}$ to around $100 \mathrm{~m} / \mathrm{s}$. These drifts correspond to perpendicular fields of about $14 \mathrm{mV} / \mathrm{m}$ and $5 \mathrm{mV} / \mathrm{m}$, respectively. Using Eq. (1) we find polarization fields well above the threshold for Type I-CSR echoes.

The discussion thus far can be summarized as follows:

1. Mesoscale F-region structures can polarize sufficiently to create sizable localized electric fields at these same mesoscales but with fields that are not as large as those observed at the scale of Q-P bands.

2. The large Hall conductivity we observed in this event coupled with observed patchiness of sporadic E layers is capable of creating the large electric fields and the Type I echoes detected by the radars. 
These results are interesting but do not yet correspond to the cause and affect relationships we naturally seek. We next attempt to at least summarize the crucial questions and, when possible, provide some suggestions:

1. Do E and F-region mesoscale structures physically move together or does one generate the other as it moves?

2. If one region dominates the apparent motion, which is it?

\section{What is the source of Type I echoes?}

Many studies of both MSTID's and regions exhibiting Q-P echoes indicate that they are slanted from NW to SE and move southwestward at many tens of $\mathrm{m} / \mathrm{s}$. This commonality has led to the notion that the two phenomena are related and to the theoretical work of Cosgrove and Tsunoda (2004) and Cosgrove et al. (2004) on the coupling of E- and F-layer instabilities.

In Fig. 3 we illustrated that our observations are consistent with this idea. We noted that slanted bands propagated across the region. One band was present in nearby Arecibo ISR data at the time when the Illinois radar detected strong scatter, presumably from the $100 \mathrm{~km}$ height range. Later another band was present when echoes were detected by CUPRI. Although we remember that the ISR and CSR radars did not probe the same volumes, taken together these bands of $\mathrm{AO}$ data and the intermittentcy of the CSR data seem to support the colocation and co-propagation of the $\mathrm{E}$ and $\mathrm{F}$ layer features.

Tsunoda (2008) has provided formulas for the coupled EF layer instabilities. Using his Eq. (5), the conductivity parameters measured by the Arecibo radar and a wind shear of $0.01 \mathrm{~s}^{-1}$, we find a growth rate of $0.007 \mathrm{~s}^{-1}$, which corresponds to an e-folding time of $150 \mathrm{~s}$. This growth is quite large compared to typical Perkins Instability growth rates. This suggests that the E-layer irregularities grow underneath a moving MSTID.

The observation of type 1 radar echoes and the large lineof-sight Arecibo drifts indicates that large electric fields were generated in this event. The polarization electric field associated with elongated patches of mid-latitude plasma is of the order of $\sigma_{H} / \sigma_{P}\left(E_{t}\right)$ where $E_{t}$ is the field component perpendicular to the patch. With the observed conductivity ratio of 10 , it is clear that the threshold for the two-stream instability, which is about $12 \mathrm{mV} / \mathrm{m}$, is easily met.

Now to questions that remain open.

1. Why is there seemingly an increase in the E-region plasma density and conductivity associated with an Fregion mesoscale height increase and sub-mesoscale intense electric fields? Is this a coincidence?

This is a bothersome question. If as we concluded above, the structured $\mathrm{E}$ region is generated under a moving MSTID, a cloud of enhanced plasma would eventually be left behind. In this scenario, the high plasma density would indeed be a coincidence. But a contributing factor to the strength of this particular event might have been the eastward drift (Fig. 5) that preceded the large westward drift, i.e., just as the layer would have been left behind, it was picked up again with the change in direction of the drift thereby allowing further growth.

2. What is the relationship between the neutral gas perturbations and the plasma disturbances?

A detailed study of this observation is beyond the scope of the present paper. Two possibilities need to be quantitatively studied. First, suppose the neutral gas is stable, then the observed sodium structure is due to recombination of sodium ions in a structured plasma (Collins, 2002). Second, suppose the neutral gas is Kelvin Helmholtz unstable to the same shear, which forms the sporadic E layer. Then the neutral structure and some or all of the plasma structure is driven by the Kelvin Helmhotz instability.

\section{Conclusions}

We conclude that the coupled E-F layer instability (Cosgrove and Tsunoda, 2004) is likely operating during this event to generate electric fields of sufficient strength to create the type 1 echoes observed. Other questions remain open, especially the one about the source of excess E-region plasma density.

Acknowledgements. This work was supported under NSF Grants ATM-9713575 and ATM-0737697 to Cornell University. The Arecibo Observatory is operated by Cornell University under a cooperative agreement with the National Science Foundation.

Topical Editor K. Kauristie thanks two anonymous referees for their help in evaluating this paper.

\section{References}

Behnke, R. A.: $F$-layer height bands in the nocturnal ionosphere over Arecibo, J. Geophys. Res., 84, 974-978, 1979.

Bowman, G. G.: The nature of ionospheric spread $F$, irregularities in mid-latitude regions, J. Atmos. Terr. Phys., 43, 65-79, 1981.

Collins, S. C., Plane, J. M. C., Kelley, M. C., Wright, T. G., Soldán, P., Rollason, R. J., Kane, T. J., Gerrard, A. J., Grime, B. W., Friedman, J. D., González, S. A., Zhou, Q., and Sulzer, M. P.: A study of the role of ion-molecule chemistry in the formation of sporadic sodium layers, J. Atmos. Solar-Terr. Phys., 64, 845860, 2002.

Cosgrove, R. B. and Tsunoda, R. T.: Instability of the $E-F$ coupled nighttime midlatitude ionosphere, J. Geophys. Res., 109, A04305, doi:10.1029/2003JA010243, 2004.

Cosgrove, R. B., Tsunoda, R. T., Fukao, S., and Yamamoto, M.: Coupling of the Perkins instability and the sporadic- $E$ layer instability derived from physical arguments, J. Geophys. Res., 109, A06301, doi:10.1029/2003JA010295, 2004. 
Farley, D. T.: A theory of electrostatic fields in a horizontally stratified ionosphere subject to a constant, vertical magnetic field, J. Geophys. Res., 64, 1225-1233, 1959.

Farley, D. T.: A theory of electrostatic fields in the ionosphere at nonpolar geomagnetic latitudes, J. Geophys. Res., 65, 869-877, 1960.

Garcia, F. J., Kelley, M. C., Makela, J. J., and Huang, C.-S.: Airglow observations of mesoscale low-velocity traveling ionospheric disturbances at midlatitudes, J. Geophys. Res., 106, 18407-18415, 2000a.

Haldoupis, C. and Schlegel, K.: Characteristics of midlatitude coherent backscatter from the ionospheric $\mathrm{E}$ region obtained with Sporadic E Scatter experiment, J. Geophys. Res., 106, 1338713398, 1996.

Haldoupis, C., Farley, D. T., and Schlegel, K.: Type-1 echoes from the mid-latitude E-Region ionosphere, Ann. Geophys., 15, 908917, 1997, http://www.ann-geophys.net/15/908/1997/.

Hysell, D. L., Yamamoto, M., and Fukao, S.: Simulations of plasma clouds in the midlatitude $E$-region ionosphere with implications for Type I and Type II quasiperiodic echoes, J. Geophys. Res., 107(A10), 1313, doi:10.1029/2002JA009291, 2002.

Hysell, D. L., Larsen, M. F., and Zhou, Q. H.: Common volume coherent and incoherent scatter radar observations of mid-latitude sporadic E-layers and QP echoes, Ann. Geophys., 22, 32773290, 2004, http://www.ann-geophys.net/22/3277/2004/.

Kelley, M. C.: The Earth's Ionosphere: Plasma Physics and Electrodynamics, International Geophysical Series, Vol. 43, Academic Press, New York, San Diego, California, 1989.

Kelley, M. C., Riggin, D., Pfaff, R. F., Swartz, W. E., Providakes, J. F., and Huang, C.-S.: Large amplitude quasiperiodic fluctuations associated with a mid-latitude sporadic- $E$ layer, J. Atmos. Terr. Phys., 57(10), 1165-1178, 1995.

Kelley, M. C., Makela, J. J., Swartz, W. E., Collins, S. C., Thonnard, S., Aponte, N., and Tepley, C. A.: Caribbean Ionospheric Campaign, Year One: Airglow and plasma observations during two intense mid-latitude spread- $F$ events, Geophys. Res. Lett., 27, 2825-2828, 2000b.

Kelley, M. C., Makela, J. J., and Saito, A.: The mid-latitude $F$ region at the mesoscale: More mysterious than ever, J. Atmos. Solar-Terr. Phys., 64, 1525-1529, 2002.

Kelley, M. C., Swartz, W. E., and Makela, J. J.: Mid-latitude ionospheric fluctuation spectra due to secondary $E \times B$ instabilities, J. Atmos. Solar-Terr. Phys., 66(17), 1559-1565, 2004.

Makela, J. J. and Kelley, M. C.: Using the 630.0-nm nightglow emission as a surrogate for the ionospheric Pedersen conductivity, 108, 1253, doi:10.1029/2003JA009894, 2003.
Martyn, D. F.: Electric currents in the ionosphere. III. Ionization drift due to winds and electric fields, transroysoc, A246, 306$320,1953$.

Mendillo, M. J., Baumgardner, J., Nottingham, D., Aarons, J., Reinisch, B., Scali, J., and Kelley, M.: Investigations of thermospheric-ionospheric dynamics with $6300 \AA$ images from the Arecibo Observatory, J. Geophys. Res., 102, 7331-7343, 1997.

Miller, K. L. and Smith, L. G.: Incoherent scatter radar observations of irregular structure in mid-latitude sporadic $E$ layers, J. Geophys. Res., 83, 3761-3775, 1978.

Otsuka, Y., Shiokawa, K., and Wilkinson, P.: Geomagnetic conjugate observations of medium-scale traveling ionospheric disturbances at midlatitude using all-sky airglow imagers, Geophys. Res. Lett., 31, 15803, doi:10.1029/2004GL02062, 2004.

Pfaff, R., Freudenreich, H., Yokoyama, T., Yamamoto, M., Fukao, S., Mori, H., Ohtsuki, S., and Iwagami, N.: Electric field measurements of DC and long wavelength structures associated with sporadic- $E$ layers and QP radar echoes, Ann. Geophys., 23, 2319-2334, 2005, http://www.ann-geophys.net/23/2319/2005/.

Saito, A., Iyemori, T., Sugiura, M., Maynard, N. C., Aggson, T. L., Brace, L. H., Takeda, M., and Yamamoto, M.: Conjugate occurrence of the electric field fluctuations in the nighttime midlatitude ionosphere, J. Geophys. Res., 100, 21439-21451, 1995.

Shalimov, S., Haldoupis, C., and Schlegel, K.: Large polarization fields associated with midlatitude sporadic $E$, J. Geophys. Res., 103, 11617-11625, 1998.

Sulzer, M. P., Aponte, N., and González, S. A.: Application of linear regularization methods to Arecibo vector velocities, J. Geophys. Res., 110, A10305, doi:10,1029/2005JA011042, 2005.

Swartz, W. E., Collins, S., Kelley, M. C., Kudeki, E., Franke, S., Urbino, J., and Aponte, N.: First observations of an $F$-region turbulent upwelling coincident with severe $E$-region plasma and neutral perturbations, J. Atmos. Solar-Terr. Phys., 64, 15451556, 2002.

Tsunoda, R.: A digest of electrodynamical coupling and layer instabilities in the nighttime midlatitude ionosphere, in: Midlatitude Ionospheric Dynamics and Disturbances, edited by: Kintner, P., Coster, A. J., Fuller-Rawell, T., Mannucci, A. J., Mendillo, M., and Heelis, R., Geophysical Monograph Series, 181, 2008.

Yamamoto, M., Fukao, S., Woodman, R., Ogawa, T., Tsuda, T., and Kato, S.: Mid-latitude $E$-region field-aligned irregularities observed with the MU radar, J. Atmos. Terr. Phys., 54, 769-777, 1992. 